\title{
Increased concentration of C4d complement protein in CSF in amyotrophic lateral sclerosis
}

\author{
Y Tsuboi, T Yamada
}

\begin{abstract}
Plasma and CSF concentrations of C4d and the circulating immune complex to C1q were measured in 27 patients with amyotrophic lateral sclerosis (ALS) or cervical spondylosis. There was no significant difference among groups in plasma C4d or in plasma or CSF concentrations of the circulating immune complex to C1q. The ALS group, however, had a significantly higher CSF concentration of C4d than the group with cervical spondylosis, as well as a higher $\mathrm{C} 4 \mathrm{~d}$ index (CSF to plasma C4d ratio $\times$ serum to CSF albumin ratio). These results suggest that augmented complement activation in the CNS occurs in ALS. Increased CSF concentration of C4d or raised C4d index may serve as a basis for differentiating ALS from cervical spondylosis.
\end{abstract}

(F Neurol Neurosurg Psychiatry 1994;57:859-861)

The cause of amyotrophic lateral sclerosis (ALS) remains unknown, but several authors have reported immunological abnormalities. These include detection of immune complexes in serum, ${ }^{12}$ increased concentrations of $\mathrm{C} 4,{ }^{2}$ deposits of $\mathrm{IgG}$ and $\mathrm{C} 3$ in the motor cortex and spinal cord, ${ }^{34}$ an IgG subclass deficiency, ${ }^{5}$ and lymphocyte infiltration into the spinal cord. ${ }^{67}$ Furthermore, on the basis of an immune animal model of motor neuron disease, Smith et $a l^{8}$ speculated that the pathogenesis of ALS may be initiated by circulating antibodies directed against specific membrane constituents.

We reported earlier the activation of complement proteins of the classical pathway in affected oligodendroglia (complement activated oligodendroglia ${ }^{910}$ ) in several neurological diseases, including ALS. ${ }^{69}$ Both these complement activated oligodendroglia and damaged myelinated axons are readily stained by antibodies to $\mathrm{C} 4 \mathrm{~d}$ and we speculated that one role of complement proteins in these structures is opsonisation..$^{910}$

The frequent appearance of $\mathrm{C} 4 \mathrm{~d}$ positive structures in various brain areas in some neurodegenerative disorders suggests that increased concentrations of this protein might be found in CSF. Recently, this possibility has been confirmed in patients with progres- sive supranuclear palsy who showed both increased concentrations of C4d in the CSF and a higher C4d index than were found in cases of Parkinson's disease or cervical spondylosis. ${ }^{11}$ Here, we found that concentrations of C4d were increased in ALS, whereas those of the circulating immune complex to C1q were not.

\section{Patients and methods}

Fifteen patients with ALS and 12 with cervical spondylosis were examined. The table gives the profiles for the ALS and cervical spondylosis groups. A Mann-Whitney U test showed that there was no significant difference in age between the groups. The diagnosis of ALS was based on the presence of both upper and lower motor neuron symptoms and signs with or without bulbar signs and with a progressive course. In the ALS group, the severities of the weakness in the bulbar muscles and in the muscles of the upper and lower extremities, and of spasticity were each rated by semiquantitative indices $(0$, none; 1 , slight; 2, moderate; and 3, severe). The table shows the mean severity scores.

After informed consent was obtained from each patient, $5 \mathrm{ml}$ of CSF was obtained by lumbar puncture. Blood was obtained at the same time. Albumin and IgG in both serum and CSF were measured. Two millilitres of CSF with $10 \mathrm{mM}$ EDTA and the plasma were used for complement analysis.

A circulating immune complex enzyme immunoassay kit (Quidel). (sandwich assay) was used for the measurement of the concentration of the circulating immune complex to C1q. Plasma specimens were diluted ( 1 to 50) before assay, but CSF samples were not. After incubation of the specimen in the microtitre well for one hour at room temperature, horseradish peroxidase conjugated goat anti-human IgG was added to each well and the mixtures incubated for 30 minutes at room temperature. After reaction with the chromogenic substrate according to the supplier's directions, the absorbances (A405 values) were measured spectrophotometrically (MRP-A4i, TOSOH). A standard curve was generated by plotting the A405 values obtained at various concentrations of the standard. Results were expressed as $\mu \mathrm{g}$ (serum) or $\mathrm{ng}$ (CSF) of heat aggregated human $\gamma$-globulin equivalents per $\mathrm{ml}$ 
Summary of the profile (mean age (SD) and sex distribution) and the means (SDs) of concentrations of complement proteins, C4d and IgG indexes, and $Q$ albumin values in patients with $A L S$ and cervical spondylosis

\begin{tabular}{|c|c|c|c|c|c|c|c|c|c|c|c|}
\hline & \multirow[b]{2}{*}{$\begin{array}{l}\text { Age } \\
(y)\end{array}$} & \multirow[b]{2}{*}{$\begin{array}{l}\text { Sex } \\
M: F\end{array}$} & \multicolumn{2}{|l|}{ Plasma } & \multicolumn{2}{|l|}{$C S F$} & \multirow[b]{2}{*}{$\begin{array}{l}\text { C4d } \\
\text { index }\end{array}$} & \multirow[b]{2}{*}{$\begin{array}{l}\text { IgG } \\
\text { index }\end{array}$} & \multirow[b]{2}{*}{$\underset{\text { albumin }}{Q}$} & \multirow{2}{*}{$\begin{array}{l}\text { Duration } \\
\text { of illness } \\
\text { (months) }\end{array}$} & \multirow[b]{2}{*}{$\begin{array}{l}\text { Score } \\
\text { of severity }\end{array}$} \\
\hline & & & $\begin{array}{l}C I C / C 1 q \\
(\mu g E q / m l)\end{array}$ & $\begin{array}{l}C 4 d \\
(\mu g / m l)\end{array}$ & $\begin{array}{l}C I C / C 1 q \\
\text { (ng Eq/ml) }\end{array}$ & $\begin{array}{l}C 4 d \\
(n g / m l)\end{array}$ & & & & & \\
\hline $\begin{array}{l}\text { ALS (n=15) } \\
\text { Cervical } \\
\text { spondylosis } \\
(n=12)\end{array}$ & $\begin{array}{l}60.5(10.4) \\
54.5(11.3)\end{array}$ & $\begin{array}{l}9: 6 \\
8: 4\end{array}$ & $\begin{array}{l}2.5(2 \cdot 7) \\
1 \cdot 7(1 \cdot 6)\end{array}$ & $\begin{array}{l}43 \cdot 0(11 \cdot 5) \\
41 \cdot 1(24 \cdot 7)\end{array}$ & $\begin{array}{l}12 \cdot 1(5 \cdot 7) \\
11 \cdot 7(6 \cdot 4)\end{array}$ & $\begin{array}{c}1173(348)^{\star \star} \\
468(178)\end{array}$ & $\begin{array}{l}5.6(2.0)^{\star} \\
2.8(1.7)\end{array}$ & $\begin{array}{l}0.4(0.1) \\
0.4(0.2)\end{array}$ & $\begin{array}{l}6.5(3.0) \\
7.0(3.0)\end{array}$ & $11 \cdot 4(5 \cdot 9)$ & $5 \cdot 2(2 \cdot 0)$ \\
\hline
\end{tabular}

${ }^{\star} \mathrm{p}<0.01 ;{ }^{\star \star} \mathrm{p}<0.001$ for differences between the ALS and cervical spondylosis groups. Score of severity was calculated by addition of the ratings $(0$, none; 1 , slight; 2, moderate; 3 , severe) assigned to indicate the degree of weakness in the bulbar muscles and those of the upper and lower extremities, as well as the degree of spasticity (maximum possible $=12$ ). CIC: circulating immune complex.

( $\mu \mathrm{g} \mathrm{Eq} / \mathrm{ml}$ or $\mathrm{ng} \mathrm{Eq} / \mathrm{ml}$ ). The detection limit of the assay, taken as $3 \mathrm{SD}$ above the mean absorbance of the zero standard, was $2 \mathrm{ng}$ $\mathrm{Eq} / \mathrm{ml}$.

To measure the C4d concentration, we developed a sandwich assay. Microassay plates were coated with human C4d antibody (mouse monoclonal, 1:100, Quidel). The specificity of the antibody has been reported earlier. ${ }^{11}$ The specimen was diluted 1 to 50 for CSF and 1 to 400 for plasma. In the second stage, we used a horseradish peroxidase conjugated human $\mathrm{C} 4$ antibody (goat polyclonal, 1:2000, binding site). The third stage was reaction with the same chromogenic substrate used in the circulating immune complex to $\mathrm{Clq}$ assay, followed by reading the absorbance at A450. Results, obtained by comparison with a standard curve generated with various known concentrations of $\mathrm{C} 4 \mathrm{~d}$ (Quidel), were expressed as $\mu \mathrm{g} / \mathrm{ml}$ of C4d for plasma and $\mathrm{ng} / \mathrm{ml}$ of $\mathrm{C} 4 \mathrm{~d}$ for CSF. The detection limit of the assay was $10 \mathrm{ng} / \mathrm{ml}$.

All assays were done in duplicate. The $Q$ albumin-CSF albumin concentration $x$ $10^{3} /$ serum albumin concentration-was calculated as an indicator of blood-brain barrier function. The CSF IgG index ((CSF IgG concentration $\times$ serum albumin concentration)/(serum IgG concentration $\times \mathrm{CSF}$ albumin concentration)) and the CSF C4d index $((\mathrm{CSF}$ C4d concentration $\times$ serum albumin

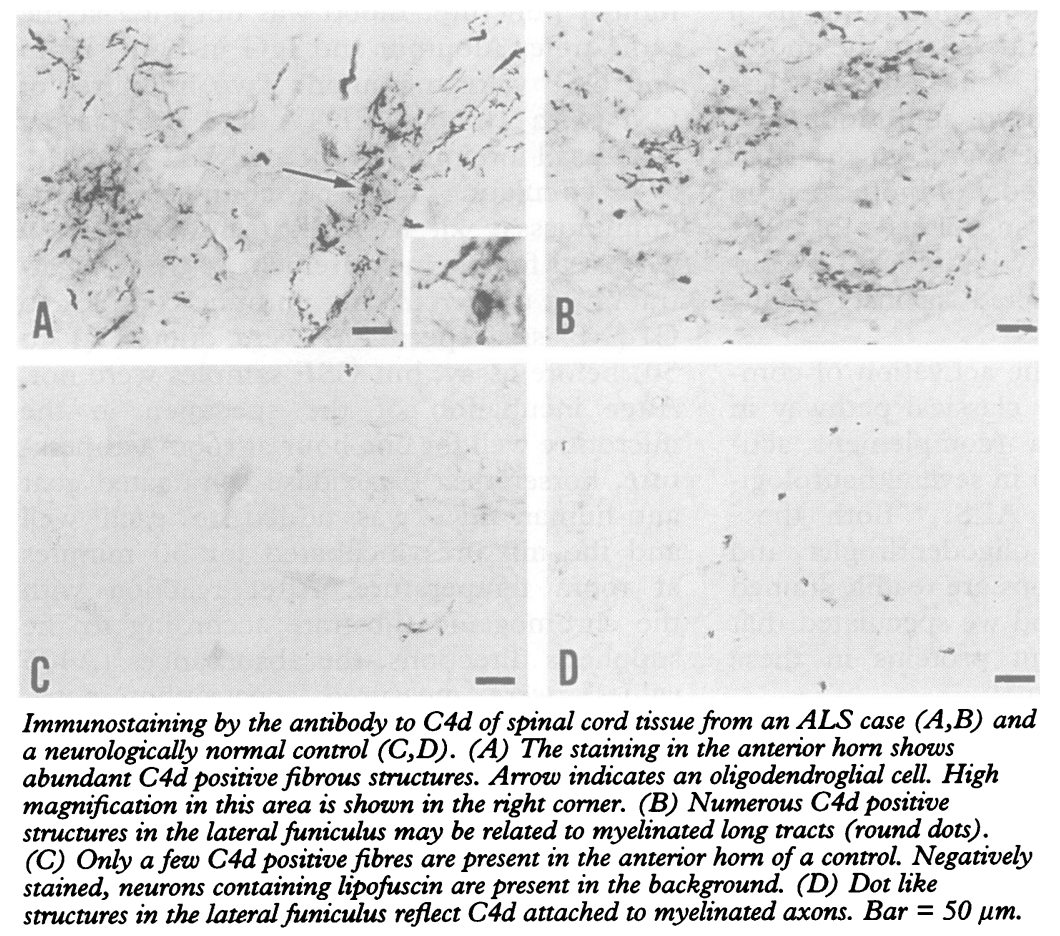

concentration)/(serum C4d concentration $\times$ CSF albumin concentration)) were taken as measures of the intrathecal synthesis of IgG or C4d respectively.

One of the patients died of respiratory failure and was confirmed pathologically as having ALS. Small blocks from the precentral cortex and high cervical spinal cord were dissected and were fixed in $4 \%$ paraformaldehyde for two days in the cold. We also used spinal cord tissue from non-neurological cases aged 65 and 70 . The cryoprotected blocks were cut at $20 \mu \mathrm{m}$ on a freezing microtome and stained by human C4d antibody (mouse monoclonal, Quidel, 1:500) as previously described. ${ }^{10}$

\section{Results}

The table shows the group means and SDs for the concentrations of the circulating immune complex to $\mathrm{C} 1 \mathrm{q}$ and $\mathrm{C} 4 \mathrm{~d}$ in plasma and CSF, the C4d and IgG indexes, and the value of $Q$ albumin.

Mann-Whitney U tests showed no significant difference between the groups in the concentrations of plasma C4d, plasma circulating immune complex to $\mathrm{Clq}$, or CSF circulating immune complex to $\mathrm{Clq}$, or in the IgG index. The value of the IgG index in all the ALS cases was below $0 \cdot 7$, which may indicate normal IgG synthesis. ${ }^{2}$ Of the variables measured, only the CSF concentrations of C4d ( $p<0.001)$ and the CSF C4d index $(p<0.01)$ showed significant differences.

The values of $Q$ albumin ranged from $2 \cdot 8$ to 13.9 in the ALS and from 3.2 to 11.8 in the group of cervical spondylosis, with the mean values not being significantly different. If a value of $<7.0$ is taken as normal, ${ }^{12}$ six $(40 \%)$ of the cases and eight $(67 \%)$ of the cervical spondylosis cases had slight to moderate damage to the blood brain barrier.

In the ALS group, the CSF C4d correlated significantly with severity scores $(r=0.76, \mathrm{p}$ $<0.01)$, with CSF IgG $(r=0.62, \mathrm{p}<0.05)$, and with $\mathrm{Q}$ albumin $(r=0.64, \mathrm{p}<0.01)$. The $Q$ albumin also correlated significantly with CSF IgG $(r=0.85, \mathrm{p}<0.01)$ and with the duration of illness $(r=0.72, \mathrm{p}<0.01)$. In the group with cervical spondylosis, no correlations were found among the variables.

Immunohistochemistry with the antibody to C4d showed abundant complement activated oligodendroglia in the precentral cortex, especially in the grey matter. Fewer complement activated oligodendroglia were seen in the spinal cord, but numerous deposits of C4d on fibrous structures were found in the anterior horn (figure (A)). In the 
lateral funiculus, dotted deposits of $\mathrm{C} 4 \mathrm{~d}$ seemed to be attached to the surface of corticospinal fibres running longitudinally (figure (B)), the same as in our previous report. ${ }^{6} \mathrm{By}$ contrast, only a few $\mathrm{C} 4 \mathrm{~d}$-positive structures were seen in neurologically normal control tissue (figure (C,D)).

\section{Discussion}

A major result of this study is the indication that the C4d concentration in the CSF and the CSF C4d index might be used to differentiate ALS from cervical spondylosis. Occasionally, the differential diagnosis between ALS and cervical spondylosis is difficult in the early stages, especially if the cervical spondylosis presents predominant motor or pure motor signs. Moreover, ALS sometimes occurs in association with cervical spondylosis.

An increased serum $\mathrm{C} 4$ concentration has been reported in ALS cases. ${ }^{2}$ In our study, the plasma C4d concentration was not significantly higher in ALS than in cervical spondylosis, but both the C4d concentrations in the CSF and the C4d index were. The exact mechanism for the increased concentrations of C4d in the CSF is unknown. These high concentrations are not surprising, however, in view of the many complement activated oligodendroglia and deposits of $\mathrm{C} 4 \mathrm{~d}$ seen immunohistochemically in ALS. ${ }^{6}$ We have not yet done immunohistochemical studies on cervical spondylosis tissue, but the low values of C4d in the CSF suggest that few complement activated oligodendroglia would be found, and this is consistent with its restricted pathology. We believe that $\mathrm{C} 3 \mathrm{~d}$ and C4d attachment to oligodendrocytes may be an early event in demyelination. ${ }^{910}$ If this is true, there may be continuous complement activation in progressive diseases with widespread pathology such as ALS or progressive supranuclear palsy. It is still not clear how the complement cascade is activated, but it may be either by IgG deposition ${ }^{4}$ or damaged myelin. ${ }^{13}$

The correlation analyses on the ALS data suggest that the blood brain barrier breakdown progresses as the disease develops, and that increases in the CSF C4d concentration reflect progressive pathology in the CNS. The evidence that CSF IgG and CSF C4d both increase as the blood brain barrier breakdown becomes more severe (as evidenced by their significant correlations with $Q$ albumin) might suggest their passage from the systemic circulation into the brain. Therefore, the increased C4d in CSF might be determined by both increased intrathecal $\mathrm{C} 4 \mathrm{~d}$ synthesis and by an influx from the systemic circulation in ALS. On the contrary, cervical spondylosis had low C4d synthesis and no clear evidence of C4d influx from the systemic circulation. These results show that CSF C4d assay may be a major diagnostic adjunct in ALS.
In our study, the circulating immune complex of $\mathrm{Clq}$ in plasma and the IgG index were not increased. These findings agree with one previous report ${ }^{14}$ but conflict with some others. ${ }^{12}$ A possible role for autoimmunity in the pathogenesis of ALS has been suggested by several groups. ${ }^{81516}$ Alterations of cellular (lymphocyte infiltration in the spinal cord) and humoral immunity in ALS have recently been extensively studied by Appel's group. ${ }^{4781617}$ According to their hypothesis, there is a possibility that complement proteins play a part in the degeneration of motor neurons. The other possibility, however, that complement activation merely reflects a secondary response to motor neuron degeneration caused by some other process ${ }^{14}$ still remains. Our data do not prove a pathogenetic role for complement proteins in ALS, but suggest they are an important phenomenon of the disease.

This research was supported by grants from the Minister of Education in Japan. We thank Dr Edith McGeer for editorial assistance.

1 Oldstone MBA, Wilson CB, Perrin LH, Norris FH. Evidence of immune complex formation in patients with amyotrophic lateral sclerosis. Lancet 1976;2:169-72.

2 Apostolski S, Bugarski-Prokopljević C, Miletić V, Pavlovic S, Filipovic S. Serum and CSF immunological findings in ALS. Acta Neurol Scand 1991;83:96-8.

3 Donnenfield H, Kascsak RJ, Bartfeld H. Deposits of IgG and $\mathrm{C} 3$ in th spinal cord and motor cortex of ALS
and and C3 in th spinal cord and motor

4 Engelhardt JI, Appel SH. IgG reactivity in the spinal cord and motor cortex in amyotrophic lateral sclerosis. Arch Neurol 1990;47:1210-6.

5 Ostermeyew-Shoaib B, Patten BM. IgG subclass deficiency in amyotrophic lateral sclerosis. Acta Neurol Scand 1993;87:192-4.

6 Kawamata T, Akiyama H, Yamada T, McGeer PL. Immunologic reactions amyotrophic lateral sclerosis brain and spinal cord tissue. Am $\mathcal{F}$ Pathol 1992;140: 691-707.

7 Engelhardt JI, Tajti J, Appel SH. Lymphocytic infiltrates in the spinal cord in amyotrophic lateral sclerosis. Arch Neurol 1993;50:30-6.

8 Smith RG, Engelhardt JI, Tajti J, Appel SH. Experimental immune-mediated motor neuron diseases: Models for human ALS. Brain Res Bull 1993;30:373-80.

9 Yamada T, Akiyama H, McGeer PL. Complement-activated oligodendroglia: a new pathogenetic entity identivated oligodendroglia: a new pathogenetic entity identi-
fied by immunostaining with antibodies to human fied by immunostaining with antibodies to human

10 Yamada T, McGeer PL, McGeer EG. Relationship of complement-activated oligodendroglia to reactive microglia and neuronal pathology in neurodegenerative disease. Dementia 1991;2:71-7.

11 Yamada T, Moroo I, Koguchi Y, Asahina M, Hirayama $\mathrm{K}$. Increased concentrations of $\mathrm{C} 4 \mathrm{~d}$ complement protein in the cerebrospinal fluids in progressive supranuclear palsy. Acta Neurol Scand 1994;89:42-6.

12 Jongen PJH, Boerbooms AMTh, Lamers KJB, Raes $B C M$, Vierwinden G. Diffuse CNS involvement in systemic lupus erythematosus: intrathecal synthesis of the 4th component of complement. Neurology 1991;40: 1593-6.

13 Vanguri P, Koski CL, Silverman B, Shin M. Complement activation by isolated myelin: Activation of the classical activation by isolated myelin: Activation of the classical pathway in the absence of myelin

14 Stevens A, Weller M, Wiethölter. A characteristic ganglioside antibody pattern in the CSF of patients with amyotrophic lateral sclerosis. $\mathcal{F}$ Neurol Neurosurg Psychiatry 1993;56:361-4.

15 Drachmann DB, Kuncl RW. Amyotrophic lateral sclerosis: an unconventional autoimmune disease? Ann Neurol 1988;26:269-74.

16 Engelhardt JI, Appel SH, Killian JM. Experimental autoimmune motorneuron disease. Ann Neurol 1989; 26:368-76.

17 Uchitel OD, Scornik F, Protti DA, Fumberg CG, Alvarez V, Appel SH. Long-term neuromuscular dysfunction produced by passive transfer of amyotrophic lateral sclerosis immunoglobulins. Neurology 1992;42:2175-80. 